\title{
Curadoria em museus antropológicos
}

Curatorship in anthropological museums

https://doi.org/10.1590/1982-02672021v29e36

\section{CAMILO DE MELLO VASCONCELLOS'}

https://orcid.org/0000-0003-1 158-5406

Universidade de São Paulo / São Paulo, SP, Brasil

RESUMO: Este artigo discute a curadoria em museus antropológicos e os desafios decorrentes das novas perspectivas de participação de sociedades indígenas que buscam na autorrepresentação dos discursos expositivos um papel mais efetivo nas instituições museológicas.

PALAVRAS-CHAVE: Museus antropológicos. Coleções etnográficas. Curadoria. Sociedades indígenas.

ABSTRACT: This article discusses the topic of curatorship in anthropological museums and the challenges arising from the new perspectives of participation of the indigenous societies that are looking for a more effective role in the museum institution by self-representation in the expository discourses.

KEYWORDS: Anthropological museums. Ethnographic collections. Curatorship. Indigenous societies.

1. Graduado e doutor em História pela Universidade de São Paulo (USP). Atualmente é professor associado na área de museologia do Museu de Arqueologia e Etnologia da USP (MAE-USP). Professor e orientador nos Programas de Pós-graduação em Arqueologia e de Pós-graduação Interunidades em Museologia da USP. Atua como professor convidado no curso de Mestrado em Museologia da Universidade Nacional da Colômbia e no curso de Mestrado em Museus e Patrimônio Histórico da Universidade Andina Simón Bolívar, do Equador. Pesquisador associado do Projeto Temático "Coletar, identificar, processar, difundir: o ciclo curatorial e a produção do conhecimento", com financiamento da Fundação de Amparo à Pesquisa do Estado de São Paulo (Fapesp).E-mail:<cmvasco@ usp.br>. 
2. Neste artigo não iremos nos deter sobre o tema das coleções arqueológicas, mesmo reconhecendo sua importância e presença marcante em muitos museus antropológicos.

3. Grupioni (2008, p. 22).

4. Cf. Vasconcellos (2012). ato de colecionar objetos e a prática do colecionismo são tão antigos quanto a existência humana e estiveram marcados, segundo diferentes critérios e práticas relacionadas ao poder, pela reunião de artefatos considerados "exóticos", especialmente de povos situados geograficamente numa dimensão longínqua e tidos como "estranhos" e/ou diferentes.

Em sua forma institucional, os museus podem ser considerados os herdeiros dessa ação colecionista e, especificamente, no caso dos museus antropológicos ou etnográficos, ${ }^{2}$ acabaram por incorporar uma visão sobre a alteridade a partir de práticas científicas que marcaram uma história muito particular, especialmente a partir da segunda metade do século XIX.

Segundo Grupioni:

O próprio surgimento da antropologia muito tem a ver com a tarefa de ordenar coleções e refletir sobre elas. $\bigcirc$ estudo e a formação de coleções etnográficas sempre estiveram no horizonte de preocupações desta ciência. Vários autores já afirmaram que, em suas origens, a antropologia esteve associada aos museus e à constituição de grandes coleções, que forneceram as bases para a produção de modelos teóricos ou para sua ilustração. ${ }^{3}$

A antropologia como disciplina e campo de atuação está voltada para o estudo e construção do conhecimento sobre a alteridade, encontrando nos museus um lócus de grande importância para a pesquisa, exibição e difusão de sua produção científica.

Inicialmente marcada pelos olhares etnocêntrico e eurocêntrico, numa abordagem de vertente evolucionista, na segunda metade do século XIX a antropologia manteve em vista a diversidade cultural, por meio de explicações e modelos baseados, sobretudo, na ideia de progresso, linearidade e numa visão teleológica da evolução histórica das sociedades.

A relação entre a disciplina e os museus, num contexto marcado pelos grandes museus enciclopédicos europeus, caracteriza-se por diferentes momentos de aproximação, distanciamento, reaproximação e, nos últimos trinta anos, por novas perspectivas de diálogo.

Assim, é possível afirmar que a antropologia nasceu nos museus conforme se organizavam as coleções etnográficas, fornecendo as bases para a produção das teorias antropológicas da segunda metade do século XIX, especialmente o evolucionismo e o difusionismo. ${ }^{4}$

Nesse sentido, os museus foram uma espécie de laboratório no qual eram testadas as hipóteses científicas sobre as diferentes culturas não europeias, de 
modo que reafirmavam um discurso pretensamente científico de poder e domínio, sobretudo em um contexto de expansão neocolonial, buscando justificar e legitimar a missão "civilizadora" em áreas que estavam sendo alcançadas pelo capitalismo industrial expansionista.

As primeiras práticas cientificas e curatoriais que ocorreram no interior dos museus de história natural, aos quais as coleções etnográficas estavam integradas, eram realizadas por naturalistas cujas pesquisas levavam à formação de coleçães de estudos, "amplamente marcadas por questões de antropologia física baseadas, sobretudo, em modelos de craniometria". ${ }^{5}$

O surgimento e a expansão dos museus antropológicos especializados ocorreram na segunda metade do século XIX europeu e estão relacionados a dois fenômenos, a saber: a consolidação dos estados nacionais e a institucionalização das principais ciências modernas, levando à criação de um grande número de museus nacionais que demonstravam em suas exposições como as sociedades europeias queriam ser vistas e, ao mesmo tempo, como enxergavam as demais sociedades, tanto no presente como no passado, numa espécie de panteão à memória dos povos e das culturas retratadas.

Segundo Russi e Abreu, desde a criação dos primeiros museus etnográficos na Europa do século XIX, como o Musée d'Ethnographie du Trocadéro, fundado em Paris em 1878 e hoje chamado Musée de l'Homme, os objetos e as coleções passaram por diferentes diretrizes conceituais.

Coleções que chamamos de 'antropológicas' são em geral provenientes de fontes muito desiguais, como pesquisas antropológicas, doações ou mesmo saques coloniais, troféus de guerras e objetos recolhidos por repressões policiais. ${ }^{6}$

Além disso, é preciso ressaltar que os interesses das instituições museológicas europeias - ou mesmo americanas - no final do século XIX, no que diz respeito ao tema da formação de coleções antropológicas ou etnográficas, não eram apenas científicos, mas também políticos. Portanto, essa relação será cada vez mais problemática e plena de contradições e tensões, tendo em vista as disputas e jogos de interesse que à época moviam cientistas, políticos e intelectuais.

Dois tipos de memória - uma colonizadora e expansionista (a europeia), e outra que tentava projetar uma imagem de modernidade de uma nação que queria se construir e consolidar (a americana) -, acabaram por ensejar discursos narrativos a partir dos mesmos pressupostos científicos, compartilhando espaços e códigos de debate muito próximos. 
7. Segundo Grupioni, (2008, p. 23), "O Museu Etnológico de Berlim, por exemplo, fundado em 1873, financiou, entre outras expedições, as de Max Schmidt, Theodor Koch-Grunberg, Emil Heinrich Snethlage, Karl von den Steinen e Curt Nimuendajú, que resultaram num considerável acréscimo de peças provenientes de grupos indígenas no Brasil ao acervo da instituição".

8. Grupioni, op. cit., p. 23.

9. Cf. Taylor (1984).
Nesse contexto encontramos - não apenas em museus europeus, mas também na América Latina - coleções de grande porte marcadas pela presença de crânios humanos, numa perspectiva de pesquisa denominada antropologia lombrosiana, que buscava detectar nessas estruturas cranianas, especialmente das sociedades não europeias, sinais de atraso, selvageria e criminalidade. No Brasil, - Museu Nacional, por exemplo, apoiou-se amplamente nas coleções de crânios formadas especialmente por João Batista de Lacerda (diretor do museu entre 1895 e 1915) para comprovar suas pesquisas ligadas à antropologia física, com a proliferação da coleta de ossos humanos entre os indígenas do país.

As expedições de cunho científico promovidas por governos estrangeiros em nosso país, com o apoio de instituições museológicas nacionais (especialmente do Museu Nacional, do Museu Paraense Emílio Goeldi e do Museu Paulista), contribuíram para institucionalizar a antropologia no Brasil, pois ao mesmo tempo que incorporaram aos nossos museus diversas coleções de artefatos provenientes dessas expedições, também concorreram para a formação de diversos museus etnológicos europeus, sobretudo alemães.?

O Brasil se destacou entre os provedores de peças etnográficas e, ainda que o colecionismo fosse uma prática de vários países europeus, deve-se reconhecer que a atividade museográfica ganhou proporções inigualáveis a partir da tradição histórico-cultural germânica, justamente a tradição que se fez mais presente no Brasil. Tal presença ocorreu tanto de forma direta, com a vinda de viajantes e pesquisadores alemães, quanto de forma indireta, por meio da produção antropológica norte-americana, fortemente ancorada no difusionismo e no determinismo geográfico herdados da tradição germânica. ${ }^{8}$

É possível que a presença e a influência dos museus alemães no Brasil se justifique porque enquanto França e Inglaterra voltavam seus interesses para suas colônias na África e na Ásia, a Alemanha, que não contava com o mesmo poder colonial, fincou seus interesses nas populações indígenas de nosso país. ${ }^{\circledR}$

Essas práticas antropológicas realizadas no interior dos museus foram contestadas a partir do final do século XIX e início do XX, especialmente por Franz Boas (1 858-1942), antropólogo alemão naturalizado norte-americano, cujo pensamento apontava que os antropólogos deveriam refletir sobre os artefatos a partir de suas funções e significados levando em conta o contexto cultural e social em que estavam inseridos.

Numa crítica aos modelos evolucionista e difusionista das exposições museológicas que privilegiavam a clássica distribuição tipológica de objetos, Boas defendia que as coleções etnográficas deveriam ser apresentadas a partir de critérios 
geográficos, privilegiando "a temática da representação das diferentes culturas a partir do seu próprio contexto, ou seja, valorizando-as numa perspectiva diacrônica". ${ }^{10}$

A partir da década de 1930 essa conexão entre antropologia e museus, outrora tão íntima, assiste a um distanciamento considerável que, segundo Stocking Jr. , ${ }^{1}$ tem relação direta com a criação dos departamentos de antropologia nas universidades, pondo fim ao que foi denominado de "era dos museus".

Muito desse distanciamento está ligado à falta de comunicação e ao salutar entrosamento que deveria ocorrer entre os museus e os departamentos de antropologia das universidades, mas, sobretudo, ao próprio contexto do desenvolvimento de novos objetos e problemáticas da pesquisa antropológica, que passou a se interessar mais por aspectos simbólicos da cultura, gerando uma estagnação nos estudos de cultura material e, consequentemente, dos museus como protagonistas desse processo até então.

Além disso, na década de 1960 o perfil do estudo das coleções etnográficas se alteraria: elas não seriam mais formadas com a coleta por meio de expedições científicas, mas sim com a preocupação sobre a organização social dos grupos indígenas, além da criação dos programas de pós-graduação em antropologia nas universidades.

Dessa maneira, a formação de novas coleções se tornou algo secundário, - que, aliado à força do estruturalismo de Lévi-Strauss e dos estudos da vida simbólica indígena, acabou criando novas perspectivas de pesquisas para a antropologia, que nesse momento abandonou o processo curatorial museológico como uma de suas principais prioridades, com a consequente perda do protagonismo dos museus nesse processo.

Regina Abreu, em seu artigo sobre os museus etnográficos e as práticas de colecionamento, mostra que a introdução de novos paradigmas na pesquisa antropológica "faz com que muitos antropólogos passem ao largo do colecionamento, chegando a ponto de não frequentarem museus etnográficos". ${ }^{12}$

Surpreendentemente, a partir da década de 1980 verifica-se uma reaproximação entre os museus e as teorias antropológicas, ou seja, tais instituições passaram a ser valorizadas como espaços de representação cultural e política dos vários grupos e categorias sociais que constavam em seus acervos.

Atualmente é possível acompanhar uma prática e um debate que vêm ocorrendo nos museus brasileiros sobre algumas experiências curatoriais e de colecionamento nas quais as sociedades indígenas assumem o protagonismo, ${ }^{13}$ promovendo novas ações de autorrepresentação que trazem consigo novos desafios para o processo curatorial.
10. Vasconcellos, op. cit., p. 131.

11. Stocking Jr. (1985).

12. Abreu, op. cit., p. 110.

13. Cf. Freire (2009). 
14. Por museus tradicionais entendo aquelas instituições constituídas a partir de um acervo formado por coleções historicamente definidas, em um espaço consagrado e com um público-alvo que é atingido por ações educativas e expositivas.

15. Esse movimento surgiu a partir da contribuição de pensadores que passaram a reivindicar uma nova prática museológica que superasse aquela tradicionalmente estabelecida, que sempre se valeu das coleções como um fim em si mesmo. Na América Latina, tal movimento teve como grande marco a Mesa Redonda de Santiago do Chile, em 1972, que apresentou a necessidade de criar um museu mais integrado a sua comunidade, pois estava muito distante da população do entorno. No México, a experiência de La Casa del Museo, com Mário Vazquez, é considerada a pioneira desse movimento. As contribuições de Hugues de Varine-Bohan, Mário Moutinho, Odalice Priosti, Miriam Arroyo, Coral Ordoñez, Marcele Pereira, além de outros profissionais, também mobilizaram ideias comprometidas com uma museologia de cunho social, ampliando os debates sobre a função social dos museus.

16. Os índios Ticuna são uma das mais importantes etnias indígenas brasileiras e habitam regiões próximas às fronteiras entre Brasil, Peru e Colômbia.
Essas práticas vêm acontecendo tanto em ações que partem de museus tradicionais de antropologia (universitários ou não) quanto de museus que foram criados por populações indígenas (Canadá, México, Colômbia, Equador, Peru, Guatemala, Paraguai e Brasil) que buscam novas formas de ocupar esse espaço político, bem como reivindicações identitárias.

Atualmente, a superação de práticas colonialistas nos museus antropológicos constitui um debate profícuo que mobiliza arqueólogos, etnólogos, museólogos e comunidades locais. Estas, inclusive, reivindicam uma prática mais democrática nos museus, buscando seu direito de autorrepresentação, por compreenderem que é preciso superar as pautas conservadoras dos museus tradicionais. ${ }^{14}$

Este debate gera novas problemáticas para o processo curatorial, uma vez que interfere em todas as etapas dessa atividade no interior dos museus, exigindo, portanto, novos procedimentos da cadeia operatória museológica, especialmente na coleta, salvaguarda e comunicação dos acervos patrimoniais.

É preciso afirmar, porém, que esse processo não ocorre da mesma maneira em todos os países e sociedades. Além disso, essa tentativa de ultrapassar práticas hierarquizantes e comprometidas com uma ciência positivista resultou de um longo processo de discussão e de superação que ocorreu no interior da própria ciência antropológica, como vimos anteriormente.

É preciso dizer também que a superação dessas práticas no âmbito dos museus antropológicos recebe uma grande contribuição do chamado movimento da Nova Museologia, ${ }^{15}$ que, com a colaboração de diversos autores e práticas museais, cria um campo fértil para discutir a intitulada museologia comunitária, compartilhada ou colaborativa.

Com isso, fica implícito que esse novo movimento deve ser visto como um processo que inclui não apenas os antropólogos, mas também museólogos, educadores e sociólogos, além de contar com o suporte de políticas públicas que, no Brasil, foram implementadas e apoiadas pelo Instituto Brasileiro de Museus (lbram), a partir de sua criação em 2009, o que conferiu ao patrimônio etnográfico e ao surgimento de novos museus indígenas uma efetiva realidade, algumas das quais serão discutidas neste artigo.

No Brasil, a primeira experiência que se destacou foi a do Museu Magüta, localizado no município de Benjamin Constant, Amazonas, que estava ligado ao Conselho Geral das Tribos Ticuna (CGTT) e que adotava uma pauta que incluía fundamentalmente a reivindicação dos Ticuna por suas terras. ${ }^{16}$

Em um contexto de muita luta e tensão entre grupos de fazendeiros locais e lideranças Ticuna, a ideia da criação do museu foi uma estratégia de autoafirmação 
e uma forma de chamar a atenção para a justiça de suas reivindicações, especialmente a demarcação de terras e o fim dos assassinatos de várias de suas lideranças, que vinham ocorrendo com frequência. ${ }^{17}$

As ações empreendidas contaram com a assessoria da antropóloga Jussara Gomes Gruber e previam a recuperação das antigas técnicas artesanais que estavam desaparecendo entre essa etnia, além do incentivo para que novos artistas aperfeiçoassem seus trabalhos.

No dia da inauguração do museu a prefeitura cercou o local com policiamento ostensivo e não permitiu sua abertura. A solenidade acabaria ocorrendo apenas três meses depois, em dezembro de 1991. Essa experiência foi reconhecida durante a Conferência Internacional do International Council of Museums, na Noruega, em 1995, e seu principal líder, Constantino Ramos Lopes Cupeatücü, foi premiado e reconhecido como dirigente de um museu que era símbolo da museologia comunitária.

Isso foi inovador no campo museal brasileiro, pois se tornou a primeira e efetiva ação de autorrepresentação indígena após um período de mais de um século de representações feitas em museus tradicionais por naturalistas e antropólogos, numa prática tradicional e sistemática de colecionamento, formação de acervos e ações curatoriais.

Mesmo com a saída de Constantino Cupeatücü por conta de divergências internas, em 1997, o museu continuou suas atividades e, atualmente, é uma referência para os alunos da rede municipal de ensino (Ticunas e não Ticunas) e para visitantes e turistas, não só do Brasil, mas também da Colômbia e do Peru.

Segundo Abreu,

O Museu Magüta constituiu uma experiência nova no panorama dos museus etnográficos. A experiência de um museu sobre índios, criado na confluência de um diálogo entre índios e antropólogos, merece ser registrada como um momento importante de passagem para um novo estilo de museu etnográfico e de prática de colecionamento. $\bigcirc$ falar sobre o outro é substituído por uma narrativa que mescla a construção da alteridade com a auto-representação e construção de si, que identifico como alteridade mínima.

A relação dos ticunas com seus artefatos vem sendo estudada por antropólogos, em experiências que relacionam as práticas de colecionamento de Curt Nimuendajú com as práticas de colecionamento dos próprios ticunas. Neste sentido, é expressivo o trabalho de Priscila Fau|haber, comparando os dois tipos de acervos e as representações a respeito deles. ${ }^{18}$

A segunda experiência digna de nota foi a exposição realizada no Museu do Índio do Rio de Janeiro em janeiro de 2002 e intitulada "Tempo e espaço na 
19. A terra dos Wajãpi já está demarcada e cada grupo vive aldeias separadas por distâncias consideráveis umas das outras, totalizando treze aldeias e uma população que vem crescendo nos últimos anos (ABREU, 2005).

20. Ibid, p. 123.

21. Ibid, p. 123.

22. Cf. Silva (2012).
Amazônia - os Wajãpi", que contou com a curadoria de Dominique Gallois antropóloga da Universidade de São Paulo (USP) que trabalha com a etnia há mais de vinte anos -, e com a participação de lideranças e membros da etnia do Amapá. ${ }^{19}$

A participação dos indígenas na seleção do acervo e na montagem da exposição foi intensa, especialmente em dois aspectos que envolveram a produção de mais de trezentos objetos (com a mobilização de todas as aldeias) e a montagem da casa Wajãpi, denominada de jurá.

Tal montagem envolveu a ida de quatro indígenas Wajãpi Matapi, Noé, Mata e Emyra) à cidade do Rio de Janeiro. Durante uma semana eles vivenciaram o estranhamento e a alteridade, o que foi considerado uma "experiência muito rica" 20 para todos os segmentos envolvidos nesse processo: os indígenas, os funcionários do museu, os visitantes, entre outros segmentos participantes do evento.

De acordo com Abreu,

$\bigcirc$ entrecruzamento de pontos de vista diferenciados - o da curadoria, o da equipe do Museu e o dos próprios índios - teve como resultado uma exposição em que a construção da alteridade wajãpi é também um processo de construção de identidades e de subjetividades. Em outras palavras, trata-se de um processo em que os diversos sujeitos são permanentemente afetados entre si transformando-se mutualmente. ${ }^{21}$

Além das duas experiências relatadas, há outras que se tornaram importantes por promover novos atores e sujeitos da pesquisa etnográfica e curatorial. É o caso da criação do Museu Kuahí dos Povos Indígenas do Oiapoque, em 2007, sob a coordenação da antropóloga Lux Vidal, da USP.

Assim, é importante notar que, no Brasil, sociedades e grupos indígenas vêm se apropriando de museus e de seus espaços expositivos, com base em um novo processo que está sendo denominado de curadorias partilhadas ou semipartilhadas. ${ }^{22}$

No Museu de Arqueologia e Etnologia (MAE) da USP ocorreram, em momentos diferentes, duas experiências significativas e de grande repercussão para um museu antropológico e universitário.

Porém, antes de nos deter e refletir sobre essas duas experiências, é necessário afirmar que essa instituição formalmente constituída na USP resultou da fusão de diferentes acervos da própria universidade. Esse processo ocorreu em 1989, a partir de uma deliberação do então reitor, o professor José Goldemberg, que, por meio de uma resolução, unificou acervos e coleções da área antropológica que à época estavam em unidades distintas e sem muita 
interação entre si, como os acervos arqueológicos e etnográficos do Museu Paulista, ${ }^{23}$ o acervo arqueológico do antigo Instituto de Pré-História, os acervos arqueológicos e etnográficos do antigo MAE e, finalmente, o acervo etnográfico Plínio Ayrosa, que pertencia ao Departamento de Antropologia da Faculdade de Filosofia, Letras e Ciências Humanas da USP.

A partir desse processo, conhecido como fusão de acervos e instituições, criou-se um novo MAE, com histórias diferentes sobre a formação de coleções, pesquisadores, corpo técnico, premissas de pesquisa e políticas de acervo diferenciadas, num processo que mobilizava (e ainda hoje mobiliza), diferentes perspectivas sobre o pensar e o agir quanto à política curatorial do museu.

Essas diferentes histórias integraram-se em uma nova instituição e constituem um desafio contemporâneo para os processos curatoriais em suas diferentes etapas. Além disso, sem dúvida contribuem para que sejam procurados novos e instigantes caminhos que permitam pensar como um museu dessa natureza poderia aproximar suas coleções dessas novas perspectivas de participação e de ações compartilhadas entre o corpo de pesquisadores, os técnicos e o público visitante.

Se pensarmos, por exemplo, na constituição dos acervos arqueológicos e etnográficos do Museu Paulista - inaugurado em 1895 -, que já contava com coleções dessa natureza e que foram formadas por concepções científicas que datavam do final do século XIX, e nas demais coleções (tanto do Museu Paulista como de outras instituições que participaram do processo de fusão aludido e que se formaram durante o século XX), percebe-se seu potencial de apresentar novos e instigantes desafios para um museu universitário, que repercutirão em políticas institucionais e em sua dinâmica interna, especialmente quanto aos rumos das práticas curatoriais como um todo.

Qual o sentido de manter, identificar, preservar, restaurar, documentar e comunicar coleções que, na verdade, não são apenas etnográficas, mas também históricas, pertencentes a sociedades indígenas que podem já ter sido extintas ou que, muitas vezes, não se reconhecem nessas coleções e artefatos, haja vista os processos dolorosos a que foram submetidas ao longo do século XX e início do XXI? Ou seja, que sentido essas coleções devem ter para a pesquisa que deseja desenvolver-se a partir de uma perspectiva mais compartilhada e comprometida, e que confira mais sentido não apenas para o pesquisador, mas especialmente para os grupos remanescentes dessas sociedades que foram espoliadas pela ação colonizadora?

Para além das ações curatoriais que visam tratar e comunicar essas coleções (dentre as quais muitas ainda necessitam ser pesquisadas, identificadas, tratadas,
23. A partir dessa data o Museu Paulista acabou assumindo sua identidade enquanto Museu de História, fundamentalmente. 
expostas e mediadas pela ação educativa), a pergunta que sempre vem à tona é: tendo em vista a transformação sofrida pelas sociedades às quais o museu busca atribuir novos sentidos, que papel essas coleções devem desempenhar?

Nesse sentido, é preciso apontar novos rumos não apenas para a pesquisa tradicional etnográfica, mas sobretudo para os grupos indígenas, de forma que possam encontrar no museu um aliado para a conformação de uma nova memória coletiva, criando novos e sensíveis processos identitários que permitam que esses grupos possam efetivamente atuar para ressignificar essas coleções à luz do presente, pois é no presente que a memória é retomada, especialmente se levarmos em conta o contexto tão grave em que estamos inseridos, haja vista a ameaça à sobrevivência das sociedades indígenas de nosso país.

A partir dessas questões e problemáticas no âmbito dessa nova instituição, experiências recentes de ações compartilhadas foram e estão sendo realizadas, de forma que gostaríamos de deixá-las registradas para ampliar as possibilidades de discussão.

A primeira delas ocorreu em 2005, sob a coordenação da etnóloga e docente Fabíola Andréa Silva, que a partir de um projeto de pesquisa intitulado Cultura material e dinâmica cultural: um estudo etnoarqueológico sobre os processos de manutenção e transformação de conjuntos tecnológicos entre os Asurini do Xingu, apoiado pela Fundação de Amparo à Pesquisa do Estado de São Paulo, pôde desenvolver estratégias de ação que possibilitaram efetivamente uma curadoria compartilhada. Tais ações compreenderam desde o contato com os objetos Asurini pertencentes à pesquisadora Regina Muller - identificação, usos e significados simbólicos dos artefatos - até atividades realizadas no MAE Ivisitas à exposição de longa duração, reservas técnicas, setores de documentação e restauro, educativo, oficinas de pintura corporal etc.), numa experiência que ainda guardamos em nossas mentes e corações por ter sido tão significativa enquanto oportunidade para efetivamente compartilhar saberes entre vários sujeitos.

A segunda experiência é a exposição temporária recentemente inaugurada (2019) no MAE-USP, intitulada "Resistência já! Fortalecimento e união das culturas indígenas. Kaingang, Guarani Nhandewa e Terena", cuja coordenação esteve a cargo da museóloga e docente Marília Xavier Cury, dos educadores Carla Gibertoni Carneiro e Maurício André da Silva, e da museóloga Viviane Wermelinger Guimarães.

Segundo Cury, 
Tal exposição desenvolve atualmente um processo colaborativo e autonarrativo com os Guarani Nhandewa, os Kaingang e os Terena do oeste paulista, visando elaborar a descolonização e indigenização do museu, processo institucional complexo, delicado e cauteloso, orientado pela tomada de decisão com os indígenas e pautado na confiança mútua. Trata-se de uma enorme responsabilidade, um grande desafio e de novas fronteiras de ação em expansão. Os trabalhos - entenda-se as discussões, informações, decisões, consolidações, pesquisas complementares, levantamento iconográfico, revisão de documentação museológica centenária etc. - apoiam a expografia em elaboração. ${ }^{24}$

Essas duas experiências de pesquisa curatorial desenvolvidas no MAE-USP, conectadas aos movimentos e organizações indígenas, ensejam críticas póscoloniais em relação ao papel dos museus antropológicos no século XXI.

Com isso, a antropologia e a museologia dedicam a esses novos paradigmas uma importância efetiva, pois a partir desses novos processos elas também se repensam como disciplinas e campos de produção de conhecimento, além de apontarem para novas relações com as instituições museológicas e com o processo curatorial como um todo.

Essas experiências, mesmo que recentes, acabam por criar novas perspectivas para os museus antropológicos, pois trazem à tona um novo fazer antropológico e museal.

Segundo Kok,

Com o intuito de inverter tais relações históricas de dominação, a vertente antropológica do multiculturalismo privilegia a 'polifonia' como saída para os museus etnográficos, 'dando voz' aos produtores dos objetos expostos ao mesmo tempo em que questiona a representatividade e o poder dos curadores. ${ }^{25}$

É importante pontuar os estudos referidos. No caso do Museu Magüta, há o exemplo efetivo de uma cultura indígena (no caso, os Ticuna) que se apropriou e inventou um museu como ferramenta para defender suas reivindicações e lutas identitárias. Os Ticuna decidiram edificar um museu a partir de suas reais necessidades de sobrevivência e encontraram, nessa realidade museal, um instrumento para fortalecer sua sobrevivência, ou seja, constituiu-se um museu enquanto processo que não estava definido a priori. É o que Andrea Roca ${ }^{26}$ definiu como "indigenização dos museus".

Por sua vez, os demais exemplos descritos e relacionados ao Museu do Índio e ao MAE-USP ocorreram em museus tradicionais que contam com acervos e coleções etnográficas que propiciaram uma experiência de ressignificação para
24. Cury (2017, p. 95).

25. Kok (2018, p.54).

26. Roca (2015). 
ambos os atores, ou seja, tanto para as populações indígenas envolvidas como para as instituições formalmente constituídas.

Assim, ao se envolverem muito de perto com essas experiências, que permitiram compreender o papel de uma instituição preservacionista convencional, criaram uma oportunidade efetiva para que os indígenas ampliassem seu entendimento de suas subjetividades, de seus processos identitários e de sua memória coletiva. Ao mesmo tempo, o corpo docente e técnico dos museus pôde repensar o processo de pesquisa curatorial a partir dessa experiência inédita para um museu constituído historicamente. Esse processo, que poderíamos denominar de curadoria e/ou de uma museologia compartilhada, acaba por nos levar a reconhecer o que se define por "fricção" 27 entre os valores da cultura do outro e a dos museus tradicionais, estabelecendo novos e instigantes debates curatoriais que devem permear toda a instituição museológica.

Para as reflexões futuras resta uma questão: que experiência e impacto permanecem para o público visitante não indígena dessas exposições?

Não seria interessante que grupos indígenas também pudessem, para além das suas autorrepresentações nos museus tradicionais, se permitirem representar as sociedades não indígenas nessas mesmas instituições, ou seja, dar a oportunidade deles dizerem como nos veem?

Dessa disputa de representações algo de muito fértil poderia ser gerado, dando ensejo a novas e profícuas discussões sobre os museus antropológicos e sobre o processo curatorial como um todo.

debate está lançado. 


\section{REFERÊNCIAS}

LIVROS, ARTIGOS E TESES

ABREU, Regina. Museus etnográficos e práticas de colecionamento: antropofagia dos sentidos. Revista do Patrimônio Histórico e Artístico Nacional, Rio de Janeiro, v. 31, 2005.

CURY, Marília Xavier. Circuitos museais para a visitação crítica: descolonização e protagonismo indígena. Ritur: Revista Iberoamericana de Turismo, Penedo, v. 7, p. 87-113, 2017. Doi: <https:// doi.org/10.2436/20.8070.01.65>.

FREIRE, José Ribamar Bessa. A descoberta do museu pelos índios. In: ABREU, Regina; CHAGAS, Mário (orgs.). Memória e patrimônio: ensaios contemporâneos. Rio de Janeiro: Lamparina, 2009. p. 207-253.

GRUPIONI, Luís Donisete Benzi. Os museus etnográficos, os povos indígenas e a antropologia: reflexões sobre a trajetória de um campo de relações. Revista do Museu de Arqueologia e Etnologia da USP, São Paulo, 20p. 21-33, 2008. Doi: <https://doi.org/10.11606/issn.2594-5939. revmaesupl.2008.113491>.

KARP, Ivan et al. (orgs.). Museum frictions: public cultures/global transformations. Durham: Duke University Press, 2006.

KOK, Glória Maria Porto. As coleções etnográficas guarani do Museu de Arqueologia e Etnologia (MAE/USP). 2018. Dissertação (Mestrado em Museologia) - Museu de Arqueologia e Etnologia, Universidade de São Paulo, São Paulo, 2018. Doi: <https://doi.org/10.11606/D.103.2019.tde03012019-100506>.

ROCA, Andrea. Acerca dos processos de indigenização dos museus: uma análise comparativa. Mana, Rio de Janeiro, v. 21, n. 1, p. 123-155, 2015. Doi: <https://doi.org/10.1590/010493132015v21n1p123>.

RUSSI, Adriana; ABREU, Regina. "Museologia colaborativa": diferentes processos nas relações entre antropólogos, coleções etnográficas e povos indígenas. Horizontes Antropológicos, Porto Alegre, v. 25, n. 53, p. 17-46, 2019. Doi: <https://doi.org/10.1590/S0104-71832019000100002>.

SILVA, Fabíola Andréa. Os Asurini do Xingu no Museu de Arqueologia e Etnologia da USP (MAE-USP). In: CURY, Marília Xavier; VASCONCELLOS, Camilo de Mello; ORTIZ, Joana Montero (coords.). Questões indígenas e museus: debates e possibilidades. São Paulo: Acam Portinari, 2012. p. 163-172.

STOCKING JR., George (ed.). Objects and others: essay on museum and material culture. Madison: University of Wisconsin Press, 1985. 
TAYLOR, Anne-Christine. L'américanisme tropical, une frontière fossile de l'ethnologie? In: RUPP-EISENREICH, Britta (org.). Histoires de l'anthropologie: XV-XIX siècles. Paris: Klincksieck, 1984. p. 213-233.

VASCONCELLOS, Camilo de Mello. Museus antropológicos e universitários: por um novo diálogo junto ao público. In: CURY, Marília Xavier; VASCONCELLOS, Camilo de Mello; ORTIZ, Joana Montero (coords.). Questões indigenas e museus: debates e possibilidades. São Paulo: Acam Portinari, 2012. p. 129-136.

Artigo apresentado em: 03/08/2020. Aprovado em: 10/10/2020.

\section{(c) BY}

